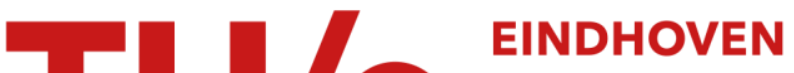

\section{Partial factors for fatigue loads in the Eurocode system for road bridge design}

Citation for published version (APA):

Hashemi, S. B., Maljaars, J., \& Snijder, H. H. (2018). Partial factors for fatigue loads in the Eurocode system for road bridge design. In C. van Gulijk, S. Haugen, A. Barros, J. E. Vinnem, \& T. Kongsvik (Eds.), Safety and Reliability - Safe Societies in a Changing World: Proceedings of ESREL 2018 (1st ed., pp. 2339-2345). Taylor and Francis Ltd.. https://www.taylorfrancis.com/books/9781351174657

Document status and date:

Published: 15/06/2018

\section{Document Version:}

Publisher's PDF, also known as Version of Record (includes final page, issue and volume numbers)

\section{Please check the document version of this publication:}

- A submitted manuscript is the version of the article upon submission and before peer-review. There can be important differences between the submitted version and the official published version of record. People interested in the research are advised to contact the author for the final version of the publication, or visit the $\mathrm{DOI}$ to the publisher's website.

- The final author version and the galley proof are versions of the publication after peer review.

- The final published version features the final layout of the paper including the volume, issue and page numbers.

Link to publication

\section{General rights}

Copyright and moral rights for the publications made accessible in the public portal are retained by the authors and/or other copyright owners and it is a condition of accessing publications that users recognise and abide by the legal requirements associated with these rights.

- Users may download and print one copy of any publication from the public portal for the purpose of private study or research.

- You may not further distribute the material or use it for any profit-making activity or commercial gain

- You may freely distribute the URL identifying the publication in the public portal.

If the publication is distributed under the terms of Article 25fa of the Dutch Copyright Act, indicated by the "Taverne" license above, please follow below link for the End User Agreement:

www.tue.nl/taverne

Take down policy

If you believe that this document breaches copyright please contact us at:

openaccess@tue.nl

providing details and we will investigate your claim. 


\title{
Partial factors for fatigue loads in the Eurocode system for road bridge design
}

\author{
S.B. Hashemi, J. Maljaars \& H.H. Snijder \\ Department of the Built Environment, Eindhoven University of Technology, Eindhoven, The Netherlands
}

\begin{abstract}
In the Eurocode system, for fatigue design of bridges, the recommended partial factor for fatigue traffic loads is set to 1 . In this paper, the adequacy of this approach is investigated by performing a reliability analysis on two types of welded joint in a main girder of a steel motorway bridge. For this purpose, a weigh in motion measurement dataset belonging to a main Dutch motorway has been compared with the fatigue load model 4 of Eurocode EN 1991-2 with respect to the stress spectrum and the fatigue damage of two structural steel details. Several structural schemes have been considered to study the effect of the shape and length of the influence line. The distributions of the stochastic variables such as dynamic amplification, accuracy of the structural model, and future traffic trends have been estimated or taken from literature. Partial factors for fatigue loads have then been calibrated in such a way that the target reliability is obtained. The influence of each stochastic variable on partial factors has been studied by derivation of the sensitivity factors. The results show that a considerably higher fatigue partial factor is required for fatigue loads on road bridges than the value of 1 currently recommended in EN 1991-2.
\end{abstract}

\section{INTRODUCTION}

Most of the parameters governing the load effects on a structure as well as the structure's response are uncertain in nature. To avoid the complexity of dealing with these random variables, standards such as Eurocode provide a deterministic model for structural design wherein characteristic values are provided for the load and the resistance and these values need to be corrected by partial factors to arrive at the design values, the latter giving the desired reliability level. In the other word, partial factors are introduced to link the deterministic models used for practical design to the required reliability level. The general equation for design of a structural component according to the Eurocode standard (EN1990, 2002) is;

$$
\frac{R_{c}}{\gamma_{M}}-\gamma_{F} \times E_{c} \geq 0 \rightarrow R_{d} \geq E_{d}
$$

where $R_{c}$ and $R_{d}$ are the characteristic and design values of the material resistance respectively, $E_{c}$ and $\mathrm{E}_{\mathrm{d}}$ are the characteristic and design values of the load effect, $\gamma_{M}$ is the partial factor for the resistance and $\gamma_{F}$ is the partial factor for the load effect. In the Eurocode system for fatigue design of bridges (EN1991-2, 2003) (EN1993-1-9, 2005), a partial factor larger than 1 is recommended only on the resistance side of the limit state $\left(\gamma_{M f}\right)$ and the partial factor on the load side $\left(\gamma_{F f}\right)$ is recommended as
1. The factor $\gamma_{M f}$ depends on the choice of fatigue assessment method as well as the consequences of failure. For the safe-life fatigue assessment method and a structure with high consequence of failure, $\gamma_{M f}$ is recommended as 1.35 . In this paper, the adequacy of these partial factors is investigated in a probabilistic approach where all influential random variables are attempted to be modelled as close to reality as possible. For this purpose, several structural schemes are defined and for each one of them, two structural details are designed to meet the Eurocode's safety requirements. Subsequently, the reliability of each designed case at the end of service life (100 years) is evaluated by the probabilistic approach and is compared with the safety requirement of the Eurocode (EN1990, 2002). Partial factors are calibrated in such a way that the deterministic design with partial factors arrives at the target reliability level.

\section{METHODS}

To consider the effects of the shape and length of the influence lines on the reliability analysis outcomes, four different structural schemes (Figure 1) with three different span lengths $(\mathrm{L}=5 \mathrm{~m}, 20 \mathrm{~m}$ and $100 \mathrm{~m}$ ) are considered. These are the same structural schemes which have been used for calibration of fatigue load models in Eurocode. Furthermore, two common structural details in 

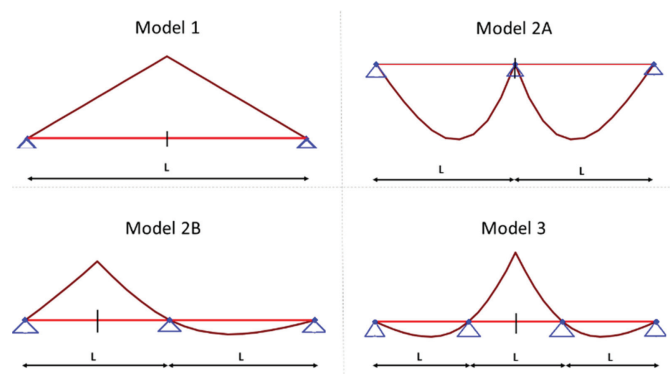

Figure 1. Structural schemes used in the analyses.
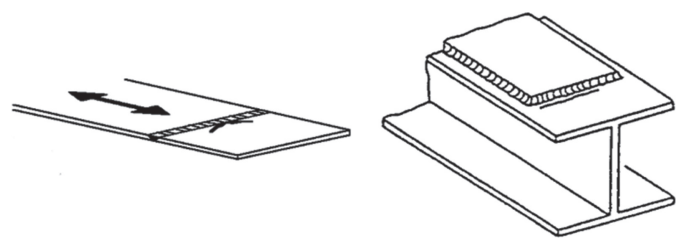

Figure 2. Left: Transverse butt welded joint (Category 80 ), Right: Cover plate (Category 50).

bridges, transverse butt weld joint and cover plate (Figure 2), are chosen to study the effect of the different $\mathrm{S}-\mathrm{N}$ curves on the partial factors.

\subsection{Deterministic approach}

The first step in the reliability analysis is to design a structure for fatigue according to the Eurocode system. For this purpose, the fatigue load model 4 (FLM4) for road bridges has been applied on the selected structural scheme (influence line) and for a fictitious cross section (section modulus) the characteristic stress spectrum will be obtained by using the rain flow cycle counting method. FLM4 is selected for this purpose because it is the most accurate fatigue load model in the Eurocodes. It consists of a set of five heavy vehicles, each having a certain axle configuration, load distribution and fraction of the total traffic volume. These are pulled over the influence line, resulting in a stress history. A rain flow counting procedure subsequently provides the characteristic stress spectrum, which is multiplied by a partial factor $\gamma_{F f}$ so as to arrive at the design stress spectrum. The design stress spectrum is to be compared to the fatigue resistance. However, because the recommended value of $\gamma_{F f}$ is set equal to 1 , the characteristic and design spectra are the same. The cumulative stress spectrum obtained for the structural scheme 3 with span length of $100 \mathrm{~m}$ is shown with solid black curve in Figure 3.

The fatigue resistance is a term referring to the capability of a specific structural detail to withstand the repetitive loads. This feature can be studied by laboratory tests and be presented by the so called S-N curve. The number of the load cycles $(\mathrm{N})$ that the detail can resist under repetitive loading with stress range $\Delta \sigma$ is recorded during the experiment and the $\mathrm{S}-\mathrm{N}$ curve is the curve fitting these points. In Eurocode (EN1993-1-9, 2005), this curve is tri-linear in log-log scale and can be presented by the following equation;

$$
\log (N)=\log \left(a_{i}\right)-m_{i} \log (\Delta \sigma)
$$

where $a$ - the $\mathrm{N}$-axis-intercept - and $\mathrm{m}$ - the negative inverse slope - are properties depending on the detail type and the index $i$ indicates two different branches of the trilinear curve. The first line $(\mathrm{i}=1)$ descends with $m_{1}=3$ until the point known as the constant amplitude (CA) fatigue limit (CAFL) which is defined at $N=5 \times 10^{6}$ cycles. To consider the effect of the variable amplitude (VA) loading, the second line $(i=2)$ is extended from the CAFL with $m_{2}=5$ until the fatigue cut-off limit at $N=10^{8}$ cycles. Damage below this cut-off value is ignored. The characteristic values of $a_{1}$ and $a_{2}$ can be calculated using (EN1993-1-9, 2005) for each detail type.

The characteristic S-N curves are divided by $\gamma_{M f}$ to obtain the design curves. These $\mathrm{S}-\mathrm{N}$ curves are shown in blue in Figure 3 for the cover plate.

Having the design stress spectrum and design $\mathrm{S}-\mathrm{N}$ curves, the fatigue damage (D) can be calculated using the Palmgren Miner damage accumulation rule (Miner, 1945). According to this rule, all stress cycles cause proportional fatigue damage which is linearly additive:

$$
D_{n}=\sum_{i} d_{i}=\sum_{i}^{n_{i}} / N_{i}
$$

where $D_{n}$ is the damage due to $n=\sum_{i} n_{i}$ cycles, $d_{i}$ is the damage caused by all stress cycles $n_{i}$ in the design stress spectrum that have the same range $\Delta \sigma_{i}$ and $N_{i}$ is the number of cycles to failure for

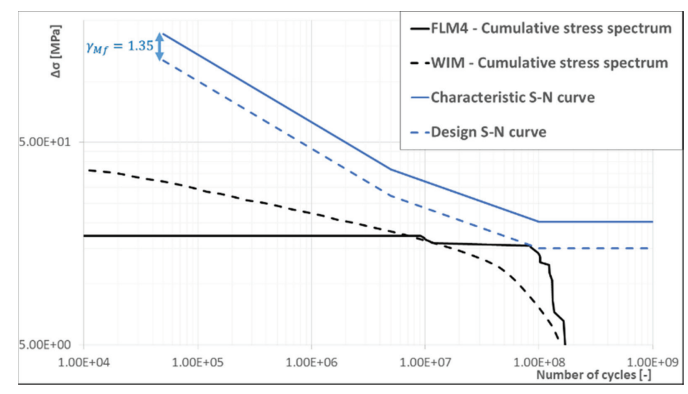

Figure 3. Deterministic cumulative stress spectra and $\mathrm{S}-\mathrm{N}$ curves for cover plate. 
that same stress range obtained from the S-N relation in equation (2).

For the structures designed by Eurocode's regulations, $D_{n}$ should be equal to or smaller than 1 at the end of life. By adjusting the section modulus in such a way that $D_{n}$ is equal to 1 , a structure is obtained that just meets the requirement for fatigue.

In the next step, to simulate the reality more accurately, a Weigh In Motion (WIM) data set belonging to a main Dutch highway (A16) is used instead of FLM4. WIM is a traffic measurement system which is able to record the speed, the number of axles, the axle loads and the axle distance of a passing vehicle as well as the distance between consecutive vehicles. In the considered WIM dataset, these traffic properties are recorded for a traffic flow in one direction and for the duration of one month. Thus, to simulate the traffic flow for the structure's entire service life of 100 years, the recorded number of $2 \cdot 10^{5}$ heavy vehicles should be multiplied by 1200 if trends are absent. The analysis is proceeded by applying the measured traffic on the previously adjusted influence line for each structural scheme and detail. This resembles the situation when a bridge is designed following Eurocode system and is loaded by actual traffic. The stress spectra for actual traffic are calculated as explained for FLM4 and in this paper are referred to as 'WIM' spectra. The WIM cumulative stress range spectrum for the case of structural scheme 3 with span length of $100 \mathrm{~m}$ is shown with dashed black curve in Figure 3. The stress range spectrum of both load models are indicated in Figure 3 for the structural scheme 3 and span length of $100 \mathrm{~m}$.

\subsubsection{Probabilistic approach}

There are several sources of uncertainty on the load side such as dynamic amplification factor (DAF), trend amplification factor $(\mathrm{t})$ and load effect model uncertainty (B). On the material resistance side, uncertainties can be considered by scatter of the fatigue test data. In the following, these random variables are described in more detail.

A DAF should be introduced to compensate for the absence of the dynamic vehicle-bridge interaction in the WIM database. Theoretical studies to determine the DAF are usually aimed at the ultimate limit state and give an exaggerated effect for a fatigue assessment. In practice, this factor can therefore be calculated as the ratio between the maximum stress recorded at the crossing of a test vehicle with high speed (e.g. $80 \mathrm{~km} / \mathrm{h}$ ) and with low speed (e.g. $20 \mathrm{~km} / \mathrm{h}$ ). Based on the strain gauge measurements carried out on some Dutch motorway bridges, DAF in this study is assumed to be distributed according to Table 1 . However, there is room for improvement of this distribution by collecting more measurement data.

The trend amplification factor takes into account possible change in load over time. The design life of important bridges is usually 100 years and in that period vehicle's number and weight can change significantly. Clearly, there is a large uncertainty in estimating trends and nevertheless, it should be estimated based on either the assumptions or extrapolation of very limited available data. The Dutch standard for assessment of existing structures (NEN8701, 2011) suggests an increase of $20 \%$ on axle loads in 100 years, i.e. a linear trend in time with an average annual increase of $0.2 \%$ with respect to the design year (Figure 4). An uncertainty over this trend increasing with time with a standard deviation of 0.05 after 100 years is assumed. The linear trend is approximately equivalent to an average increase of $10 \%$ in axle loads over the entire life with a standard deviation of $9 \%$. The annual loads are thus multiplied by factor (t) which is statistically distributed as

Table 1. Distribution of random variables.

\begin{tabular}{|c|c|c|c|c|}
\hline \multicolumn{2}{|l|}{ Variable } & \multirow{2}{*}{$\begin{array}{l}\text { Distribution } \\
\text { Log-normal }\end{array}$} & \multirow{2}{*}{$\frac{\text { mean }}{1}$} & \multirow{2}{*}{$\frac{\text { STD }}{0.05}$} \\
\hline DAF & Dynamic amplification factor & & & \\
\hline $\mathrm{t}$ & Trend amplification factor & Normal & 1.1 & $9 \mathrm{E}-4$ \\
\hline B & Load effect model uncertainty & Log-normal & 1 & 0.1 \\
\hline $\log _{10}\left(a_{1}\right)^{*}$ & Material parameter-1st line (Butt weld joint) & Normal & 12.42 & 0.25 \\
\hline $\log _{10}\left(a_{2}\right)^{*}$ & Material parameter-2nd line (Butt weld joint) & Normal & 16.07 & 0.32 \\
\hline $\log _{10}\left(a_{1}\right)^{*}$ & Material parameter-1st line (Cover plate) & Normal & 11.69 & 0.18 \\
\hline $\log _{10}\left(a_{2}\right)^{*}$ & Material parameter-2nd line (Cover plate) & Normal & 15.02 & 0.3 \\
\hline$D_{c r}$ & Critical fatigue damage & Log-normal & 1 & 0.3 \\
\hline
\end{tabular}

${ }^{*} a_{1}$ and $a_{2}$ are fully correlated. 


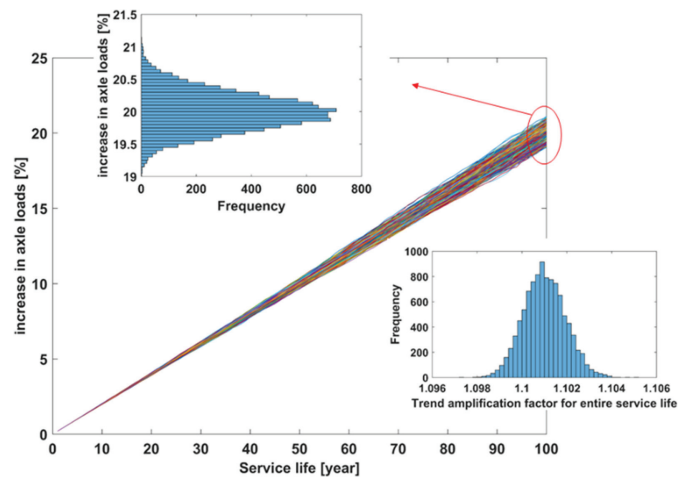

Figure 4. Trend amplification factor distribution.

shown in Figure 4 and is presented in Table 1. A possible change in number of vehicles is not considered. Background of this assumption is that the considered highway - containing 3 lanes per traffic direction - is believed to have reached is maximum capacity. A higher number of vehicles is expected to result into significant traffic jam and thus no larger number of passing vehicles.

Section 2.1.1 demonstrates that an influence line is required to determine the stress ranges. In practice, such an influence line is subtracted from a structural model of the bridge. The model may contain approximations and errors, so this influence line might be different from reality. The uncertainty related to this issue is known as the load effect model uncertainty. By comparing the calculated influence line with the influence line derived from the measurement, this uncertainty can be evaluated. In this study, the JCSS (JCSS, 2001) recommendation is used for the distribution of the load effect model uncertainty (Table 1).

The fatigue resistance is known for its significant scatter. This is mainly due to the uncontrollable differences in test samples. For simplicity, the slopes of the fitted lines $m_{1}$ and $m_{2}$ are assumed to be constant and the scatter is presented by the random variables $a_{i}$ in Equation (2). EN 19931-9 includes the characteristic lines having 95\% probability of survival and the scatter is not mentioned. Therefore, in this research, the standard deviations of the logarithm of $a_{i}\left(\log (a)_{S T D, i}\right)$ are taken from the British standard (BS7608, 2014). Starting with the characteristic values $a_{1}$ and $a_{2}$ from Eurocode (EN1993-1-9, 2005), their mean values can be obtained as;

$$
\log (a)_{\text {mean }, i}=\log (a)_{\text {characteristic }, i}+1.645 \log (a)_{S T D, i}
$$

Having the distribution parameters for all random variables, reliability analysis can be performed to evaluate the safety status of the designed details at the end of the service life. Figure 5 shows the WIM cumulative stress spectrum and its lower $(5 \%$ fraction) and upper (95\% fraction) bounds for the structural scheme 3 with span length of $100 \mathrm{~m}$ as well as the mean $\mathrm{S}-\mathrm{N}$ curve and $\mathrm{S}-\mathrm{N}$ curves with $5 \%$ and $95 \%$ probability of survival for a cover plate detail including all random variables introduced above.

\subsection{Reliability analysis}

The limit state function is defined as;

$$
g(\boldsymbol{X})=D_{c r}-D_{n}(\boldsymbol{X})
$$

where the random variable $\mathrm{D}_{\mathrm{cr}}$ is the critical damage, $\mathrm{D}_{\mathrm{n}}$ is the fatigue damage at the end of life and $\mathbf{X}$ is the vector of all previously mentioned random variables. $D_{\text {cr }}$ follows a lognormal distribution with parameters according to Table 1 (JCSS, 2001). Failure can be defined as the situation wherein $g(\boldsymbol{X})<0$. Therefore, probability of failure is defined as;

$$
P_{f}=P[g(\boldsymbol{X})<0]=\int_{g(x)<0} f_{x}(\boldsymbol{X}) d x
$$

where $f_{x}(\boldsymbol{X})$ is the multivariable probability density function of $\mathbf{X}$. First Order Reliability Method (FORM) is used to approximate the integral in equation (6). FORM, developed by (Hasofer \& Lind, 1974) is based on the idea that in the standard normal space, the reliability index, $\beta$, is the shortest distance from origin to the limit state surface $g(\boldsymbol{U})=0$, where $\mathbf{U}$ is the vector of normalized random variables. The point $\mathbf{u}^{*}$ on the limit state surface which has the shortest distance to the origin is known as the design point or the most probable failure point. Finding the design point is an iterative process and once calculated, the reliability index is

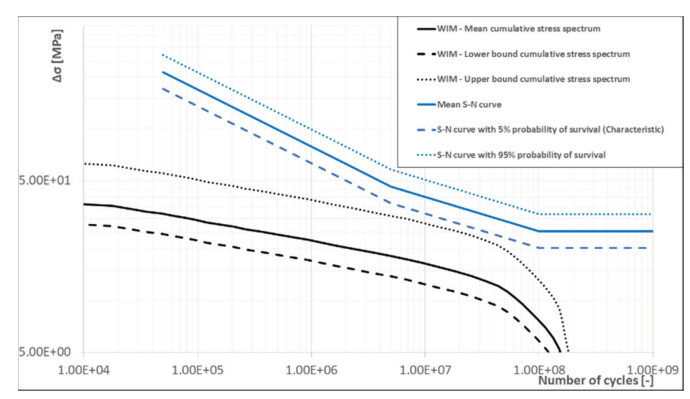

Figure 5. Probabilistic cumulative stress spectra and S-N curves for cover plate including all random variables. 
obtained. Another direct outcome of the FORM is the sensitivity factor of each random variable, $\alpha_{i}$, which is a measure for the relative importance of the standard deviation of the $\mathrm{i}^{\text {th }}$ random variable to the reliability index. It can be calculated as;

$$
\alpha_{i}=-u_{i}^{*} / \beta
$$

Sensitivity factors are used for derivation of partial factors according to the following equation;

$\gamma_{f i}=\frac{\left[1-\alpha_{i} \beta_{t} \operatorname{STD}\left(E_{i}\right)\right] \times \text { mean }\left(E_{i}\right)}{\text { characteristic }\left(E_{i}\right)}$

where $\beta_{t}$ is the target reliability index (Section 2.1.4), $E_{i}$ is the $\mathrm{i}^{\text {th }}$ random variable and $\gamma_{f i}$ is the required partial factor for $E_{i}$

Fatigue design factor (FDF) is defined as the multiplication of partial factors of resistance and load effect random variables;

$$
F D F=\prod_{i} \gamma_{M f i} \times \prod_{j} \gamma_{F f j}=\gamma_{M f} \times \gamma_{F f}
$$

The accuracy of FORM is checked by a Crude Monte Carlo (CMC) simulation with $4 \times 10^{6}$ number of samples. In this method, the probability of failure can be calculated as the ratio of the number of failure cases $(g(\boldsymbol{X})<0)$ over the total number of $\mathrm{CMC}$ samples. Having the probability of failure, the reliability index can be calculated as;

$$
\beta=-\Phi^{-1}\left(P_{f}\right)
$$

where $\Phi^{-1}($.$) is the inverse cumulative normal dis-$ tribution function.

\subsection{Target reliability index}

Target reliability index $\left(\beta_{t}\right)$ is the answer to the question "What level of safety is sufficient?". Several factors play a role in this answer, including the consequence of failure in terms of both loss of human life and economical aspects, the required cost for improving safety, the structure's planned service life and the type of considered limit state. In Eurocode, $\beta_{t}$ for fatigue limit state is ranging between the target values of the reliability indices for the ultimate and serviceability limit states. For the structures such as bridges which can be categorized into the consequence class 3 (EN1990, 2002), with details having large consequences of failure and that are designed according to the safe life concept, the target reliability index for fatigue is set equal to the ultimate limit state value of 4.3.

\section{RESULTS AND DISCUSSIONS}

Having in mind that the results of this study are widely dependent on the assigned distributions of the random variables, the reliability indices at the end of life for both cover plate and transverse butt welded joint and for the all structural schemes are shown in Figure 6. For all considered cases, the reliability index is lower than the target value when applying the recommended values of partial factors. In addition, it can be observed that the value of $\beta$ depends on the shape and length of the influence line. This is caused by the approximations and simplifications in the fatigue load model FLM4. Furthermore, it can be observed that the cover plate results in slightly higher reliability at the end of life than the transverse butt weld joint, due to the differences in scatter of the fatigue resistance (Table 1).

The corresponding fatigue design factors for each detail and structural scheme and under the WIM spectra (structure designed with characteristic FLM4 and loaded by WIM measured traffic) are shown in Figure 7.

For the span length of $100 \mathrm{~m}$ and especially for Model 2A, the values of FDF are much higher than the value resulting from the recommended

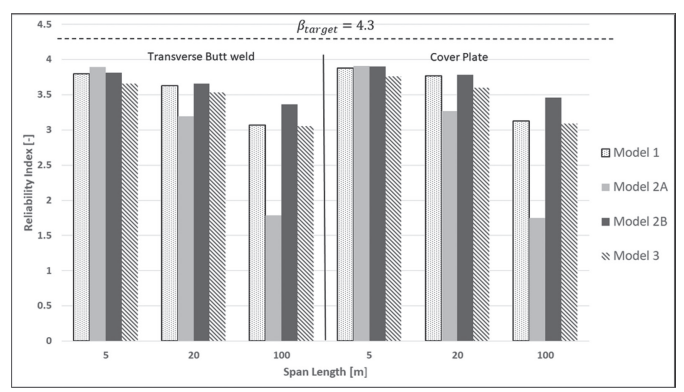

Figure 6. Reliability indices at the end of life.

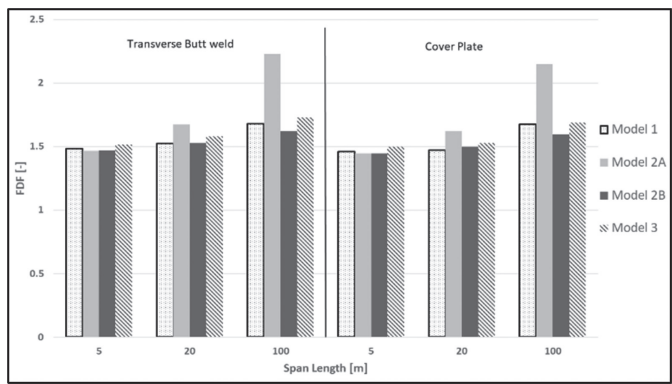

Figure 7. Required fatigue design factors to reach the target reliability index at the end of service life. 
partial factors and these are not in line with the other values. The reason is the deficiency of FLM4 to simulate the real traffic flow for the bridges with very long span. In the Dutch national annex to EN 1991-2 (EN1991-2/NB, 2011), this flaw is fixed by introducing a second heavy vehicle on the bridge in $20 \%$ of the number of heavy vehicle crossings for continuous positive or negative influence lengths larger than $60 \mathrm{~m}$. The center to center distance between these two vehicles is set as $50 \mathrm{~m}$.

Repeating the reliability analysis with FLM4a according to the Dutch NA, the values of FDF for the span length of $100 \mathrm{~m}$ are reduced to the values presented in Figure 8. These values can still be as high as 1.92 for model $2 \mathrm{~A}$ but usually fatigue is not the dominant failure mode at location of the intermediate support of a two span bridge. This example - and the still significant differences between the various structural schemes-demonstrate the necessity of updating the fatigue load models in the Eurocode.

Now that the FDF is determined, the next step is to distribute this over $\gamma_{M f}$ and $\gamma_{F f}$. A direct determination of the partial factors based on the FORM sensitivity factors is problematic, because:

- for fatigue the three-branch S-N curve uncertainty is related to the number of cycles and not to the stress range, and;

- the entire stress range spectrum influences the reliability instead of a single stress value. As demonstrated in Figure 3, the shape of the stress range spectrum of FLM4 is not in agreement with that of the WIM data.

For this reason, an intermediate step is taken where the section modulus is determined using the $\mathrm{S}-\mathrm{N}$ curve as resistance model and the WIM database as load model. In this case, the uncertainty on the load side is captured in the multiplication of the DAF, $t$ and $\mathrm{B}$. This results in a single multiplication factor for the stress spectrum and hence

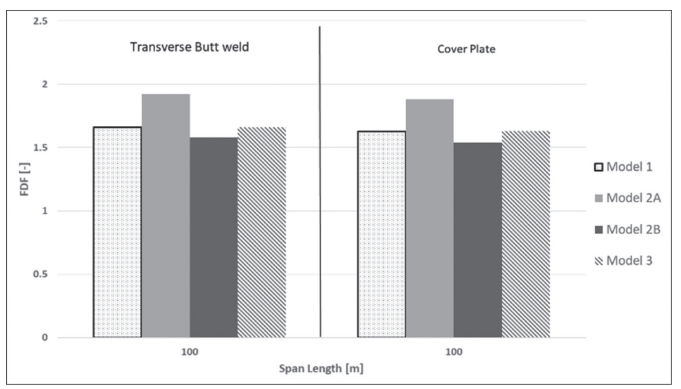

Figure 8. Required FDF after modification of FLM according to the Dutch national annex.
Table 2. Sensitivity factors of random variables.

\begin{tabular}{lrlllll}
\hline Variable DAF & t & B & $\log _{10}\left(\mathrm{a}_{1}\right) \log _{10}\left(\mathrm{a}_{2}\right)$ & $\mathrm{D}_{\text {cr }}$ \\
\hline$\alpha$ & -0.268 & -0.0044 & -0.534 & 0.0739 & 0.728 & 0.329 \\
$\sum \alpha^{2}$ & 0.357 & & 0.643 & & \\
$\gamma_{F f i}^{*}$ & 1.06 & 1.1 & 1.23 & & & \\
\hline
\end{tabular}

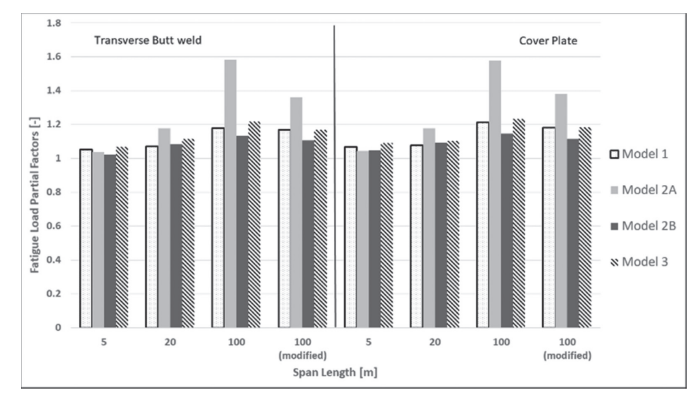

Figure 9. Fatigue load partial factors.

enables the determination of a modified partial factor for the load side, $\gamma_{F f}{ }^{*}$, via the influence factors $\alpha_{t}, \alpha_{D A F}$ and $\alpha_{B}$. Note that $\gamma_{F f}{ }^{*}$, considers the uncertainties related to the load side but not the inaccuracy of FLM 4 to represent the WIM measurement. The same analysis gives the modified fatigue design factor $\mathrm{FDF}^{*}$ and the partial factor on the resistance side can now be determined as $\gamma_{M f}=\mathrm{FDF}^{*} / \gamma_{F f}^{*}$. Finally, the partial factor on the load side including the difference between the actual WIM data and the FLM4 model is determined with the FDF of the original analysis of Figures 7 and 8 , via $\gamma_{F f}=\mathrm{FDF} / \gamma_{M f}$.

As expected, the factors $\mathrm{FDF}^{*}, \alpha_{t}, \alpha_{D A F}, \alpha_{B}$ and $\gamma_{M f}$ are almost independent on the structural models - variation of less than $2 \%$. This demonstrates the consistency of the approach.

Table 2 presents the sensitivity factors of all random variables as well as $\gamma_{F f}{ }^{*}$ values for the transverse butt welded joint located on model $2 \mathrm{~B}$ with span length of $20 \mathrm{~m}$.

For the case of transverse Butt welded joint, the value calculated for $\gamma_{M f}$ is 1.42 (i.e. $5 \%$ higher than Eurocode's recommendation) and for the case of cover plate it is equal to 1.37 (1.8\% higher than Eurocode's recommendation). The calculated values of $\gamma_{F f}$ are presented in Figure 9. It can be observed that for all considered cases, $\gamma_{F f}$ has a value larger than Eurocode's recommended value of 1. Considering all studied structural schemes with all assigned span lengths and for both structural details, $\gamma_{F f}$ takes the average value of 1.16 with standard deviation of 0.13 . 


\section{CONCLUSION}

In this paper the necessity of increasing the values of partial factors for fatigue traffic load models in Eurocode to design a steel bridge with the safe-life assessment approach has been studied. For this purpose, two different structural details located in twelve structural schemes have been designed to meet the Eurocode's fatigue safety requirements. After studying the random variables which influence the fatigue limit state and assigning a distribution to each one of them, each designed detail has been loaded by measured traffic and reliability analysis has been performed to evaluate the safety status of the detail at the end of its life. It has been observed that in all cases, the reliability index is lower than the minimum acceptable value set by the standard. The reliability depends on the structural detail as well as the shape and length of influence line. The study has been proceeded by calculating the values of the partial factors that are needed to reach the standard's target reliability level. The calculated fatigue resistance partial factors are 1.37 and 1.42 for the two steel details considered and these values are slightly higher than the recommended factor of 1.35 in the Eurocodes. The main finding of this study is that the value of fatigue load partial factor recommended by the Eurocodes is too low for fatigue load model FLM4. For all studied structural schemes and for both chosen details, the required load partial factors $\gamma_{F f}$ are higher than the factor 1 as recommended by the Eurocodes. The factor $\gamma_{F f}$ strongly depends on the shape and length of influence lines and varied between 1.02 and 1.58 for the considered systems.

The values presented should not be considered as 'the truth' because they are subjected to the choices of the distributions of load related variables. Nonetheless, it is clear that the recommended partial factor of 1 in the current Eurocodes is too small and the large differences in the calculated factors demonstrate the necessity of improving the fatigue load models in the Eurocode.

A sensitivity analysis to study the effect of the most influential load related random variables on the partial factors is another outcome of this study.
It has been found that load effect model uncertainty has a large impact on the results, followed by the load trend amplification factor. Dynamic amplification factor has a lower influence than the other variables. Based on this analysis, future studies can be planned to evaluate the distribution parameters of these random variables.

\section{ACKNOWLEDGEMENTS}

The authors would like to thank the Dutch infrastructure asset owners ProRail and Rijkswaterstaat as well as the Netherlands Organization for Applied Scientific Research (TNO) for their supports.

\section{REFERENCES}

BS7608, 2014. BS 7608, BSI Standards Publication: Guide to fatigue design and assessment of steel products, s.l.: s.n.

EN1990, 2002. EN 1990, European Committee for Standardization. Eurocode: Basis of structural design, s.1.: s.n.

EN1991-2/NB, 2011. Nationale bijlage bij NEN-EN 1991-2+C1. Eurocode 1: Belasting op constructiesDeel 2: Verkeerbelasting op bruggen, s.l.: s.n.

EN1991-2, 2003. EN 1991-2, European Committee for Standardization. Eurocode 1: Actions on structures, s.l.: s.n.

EN1993-1-9, 2005. EN1993-1-9, European committee for standardization. Eurocode 3: design of steel structures, s.l.: s.n.

Euler, M. U.K., 2013. Statistical intervals for evaluation of test data according to Eurocode 3 part 1-9, s.1.: s.n.

Hasofer A., L.N., 1977. An exact and invariant first order reliability format, s.1.: Proc. ACSE, J. Eng. Mech. Div.

Hasofer, A. \& Lind, N., 1974. An exact and invariant first order reliability format, s.1.: Proc. ASCE, J. Eng. Mech. Div.

JCSS, 2001. JCSS, Joint committee of structural safety. Probabilistic model code, s.l.: s.n.

Miner, M., 1945. Cumulative Damage in Fatigue, Journal of Applied Mechanics, s.1.: Journal of Applied Mechanics.

NEN8701, 2011. NEN 8701, Assessment of existing structures in case of reconstruction and disapproval actions, s.1.: s.n. 